Rakenteiden Mekaniikka (Journal of Structural Mechanics)

vol. 53, nro. 2, 2020, s. 42-52

http://rakenteidenmekaniikka.journal.fi/index

https://doi.org/10.23998/rm.82681

(C) 2019 kirjoittajat

Vapaasti saatavilla CC BY 4.0 -lisenssin mukaisesti

\title{
Lisähuomioita energiataseiden käytöstä virtauslaskennassa
}

\author{
Eero-Matti Salonen ${ }^{1}$ ja Rauno Holopainen
}

Tiivistelmä Artikkeli on täydennys tämän lehden aikaisempaan energiataseiden käyttöä koskevaan artikkeliin [1]. Mekaanisen energian taseen periaatteessa kokoonpuristuvassa virtauksessa esiintyvä niin sanottu kokoonpuristumistermi otetaan mukaan tarkasteluun. Eräs havainnollistava esimerkkitapaus käydään yksityiskohtaisesti läpi. Lisäksi esitetään kritiikkiä virtauslaskennan esityksissä ilmeneviin epätäsmällisyyksiin, joita saattaa esiintyä energiatarkastelujen yhteydessä.

Avainsanat: putkivirtauslaskenta, energiataseet, kokoonpuristumistermi

Vastaanotettu: 26.6.2017. Hyväksytty: 5.2.2019. Julkaistu verkossa: 30.3.2020.

emeritusprofessori Tapio Salmen muistolle

\section{Johdanto}

Tämän lehden artikkelissa [1] on käsitelty energiataseiden soveltamista virtaus-laskennassa ja erityisesti kanavistovirtauksissa. Kyseisessä artikkelissa kuvattiin varsinaisen energian taseen periaatteen ja mekaanisen energian taseen periaatteen saamia makroskooppisia muotoja ja niiden samankaltaisuuksia, mutta myös tärkeitä eroja kuitenkin ilman varsinaisia esimerkkilaskelmia. Erityisesti pyrittiin korostamaan mekaanisen energian taseen periaatteen usein liian vähälle jäävää asemaa. Tämän kirjoituksen tarkoituksena on täydentää artikkelia [1] muun muassa käymällä yksityiskohtaisesti läpi eräs havainnollistava esimerkkilaskelma. Tämän yhteydessä joudutaan ottamaan huomioon myös niin sanotun kokoonpuristumistermin osuus, joka jätettiin käsittelemättä artikkelissa [1]. Lisäksi esitetään kritiikkiä virtauslaskennan kirjallisuudessa joissain esityksissä energiatarkasteluiden yhteydessä ilmeneviin epätäsmällisyyksiin.

\footnotetext{
${ }^{1}$ Vastuullinen kirjoittaja: eeromatti.salonen@gmail.com
} 


\section{Perusyhtälöt}

Artikkelissa [1] tarkasteltiin energian taseen periaatteiden virtauslaskennassa saamia versioita. Toistetaan vielä käytetyt periaatteet.

Energian taseen periaate eli termodynamiikan ensimmäinen pääsääntö on tehomuotoisena

$$
P_{\mathrm{ext}}+P_{\mathrm{Q}}=\frac{\mathrm{D} K}{\mathrm{D} t}+\frac{\mathrm{D} E}{\mathrm{D} t}
$$

eli kappaleeseen vaikuttavien ulkoisten voimien teho $P_{\text {ext }}$ plus kappaleen saama lämpöteho $P_{\mathrm{Q}}$ on yhtä suuri kuin kappaleen liike-energian $K$ plus kappaleen sisäenergian $E$ muutosnopeus.

Mekaanisen energian taseen periaate on tehomuotoisena

$$
P_{\mathrm{ext}}+P_{\mathrm{int}}=\frac{\mathrm{D} K}{\mathrm{D} t}
$$

eli kappaleeseen vaikuttavien ulkoisten voimien teho $P_{\text {ext }}$ plus kappaleeseen vaikuttavien sisäisten voimien teho $P_{\text {int }}$ on yhtä suuri kuin kappaleen liike-energian $K$ muutosnopeus.

Artikkelissa tarkasteltiin erityisesti kuvan 1 mukaista yksidimensioista kontrollialuetta.

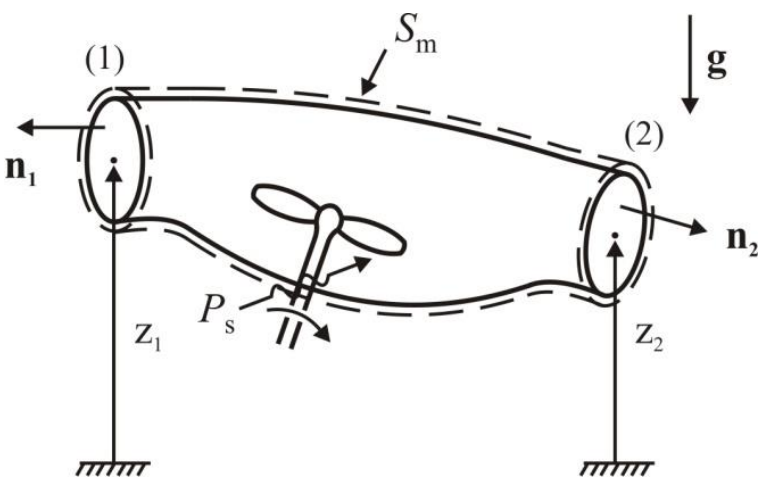

Kuva 1. Kaksiaukkoinen kontrollitilavuus.

Artikkelissa esitettyjen tavanomaisten otaksumien (tärkein niistä on pysyvän virtauksen otaksuma) jälkeen saatiin vastaavasti versiot (energian tase):

$$
Q_{1}\left[p_{1}+\alpha_{1} \frac{1}{2} \rho_{1}\left\langle v_{e}\right\rangle_{1}^{2}+\rho_{1} g z_{1}+\rho_{1} e_{1}\right]-Q_{2}\left[p_{2}+\alpha_{2} \frac{1}{2} \rho_{2}\left\langle v_{e}\right\rangle_{2}^{2}+\rho_{2} g z_{2}+\rho_{2} e_{2}\right]=-P_{\mathrm{Q}}-P_{\mathrm{S}}
$$

ja (mekaanisen energian tase):

$$
Q_{1}\left[p_{1}+\alpha_{1} \frac{1}{2} \rho_{1}\left\langle v_{e}\right\rangle_{1}^{2}+\rho_{1} g z_{1}\right]-Q_{2}\left[p_{2}+\alpha_{2} \frac{1}{2} \rho_{2}\left\langle v_{e}\right\rangle_{2}^{2}+\rho_{2} g z_{2}\right]=D-\int_{V} p d_{i i} \mathrm{~d} V-P_{\mathrm{s}}
$$


Käytettyjen merkintöjen sisältö on esitetty yksityiskohtaisesti artikkelissa [1]. Eräät termit tulevat kuitenkin selostetuksi myös tässä jatkossa tapahtuvien käsittelyjen yhteydessä. Etenkin yhtälössä (4) on nähtävissä niin sanotun "yleistetyn Bernoullin yhtälön" painetermi, liike-energia- eli nopeustermi ja korkeusasematermi. Yhtälöiden (3) ja (4) vertailu antaa yhteyden

$$
D-\int_{V} p d_{i i}=-Q_{1} \rho_{1} e_{1}+Q_{2} \rho_{2} e_{2}-P_{\mathrm{Q}}
$$

eli

$$
D=w\left(e_{2}-e_{1}\right)-P_{\mathrm{Q}}+\int_{V} p d_{i i}
$$

Tässä on käytetty hyväksi tietoa massavirran $w$ vakioarvosta eli $w=\rho_{1} Q_{1}=\rho_{2} Q_{2}$. Artikkelissa [1] ei käsitelty yhtälön (6) oikean puolen viimeisen termin — niin sanottu kokoonpuristumistermi (engl. compression term) tai dilataatiotermi - kanavisto-tyyppisessä virtauksessa saamaa arvoa. Se on esitetty nyt tämän artikkelin liitteessä ja sitä tullaan tarvitsemaan jatkossa käsiteltävän esimerkkitapauksen yhteydessä. Erityisesti otaksumalla kokoonpuristumaton virtaus dilataationopeus $d_{i i}=0$ ja yhtälö (6) saa yksinkertaisemman muodon

$$
D=w\left(e_{2}-e_{1}\right)-P_{\mathrm{Q}}
$$

Yhtälöt (6) ja (7) ovat tärkeitä verrattaessa mekaanisen energian taseen periaatteen antaman niin sanotun dissipaatiotermin (engl. dissipation term) eli häviötermin (engl. loss term) eli vastustermin (resistance term) eli kitkatermin (friction term) $D$ yhtälöiden oikeilla puolilla esiintyviin varsinaisen energian taseen periaatteen antamiin vastineisiin, jotka koostuvat sisäenergian ja lämmön vuotermeistä. Todettakoon, että niin sanottuihin "häviöihin" liittyvä terminologia — kuten yllä — voi olla alan kirjallisuudessa melko vaihtelevaa, etenkin koska oleelliset yhtälöt (3) ja (4) saadaan myös vaihtoehtoisiin muotoihin esimerkiksi jakamalla puolittain tilavuusvirralla $Q_{1}$. Tällöin yhtälöiden termeillä on paineen dimensio ja puhutaankin muun muassa painehäviöistä (engl. pressure losses).

\section{Esimerkkitapaus}

\section{Tehtävän kuvaus}

Geometria on kuvan 1 tapauksen pelkistetty versio, kuva 2. Kyseessä on pystysuorassa asemassa oleva suora (pituus $L$ ) vakioympyräpoikkileikkauksen (halkaisija $d$ ja poikkileikkauspinta-ala siis $A=\pi d^{2} / 4$ ) omaava kanavaosuus. Akselitehoa ei ole mukana eli termi $P_{\mathrm{s}}=0$. Kanavaosuuden pituuskoordinaatti $x$ on suunnattu alemmasta poikkileikkauksesta 1 ylempään poikkileikkaukseen 2. Väliaineena on ilma, jossa kosteuden mahdolliset muutokset jätetään tässä huomiotta. Erityisesti nyt halutaan tarkas- 
tella myös kokoonpuristuvaa virtausta, jolloin käsittely mutkistuu huomattavasti verrattuna kokoonpuristumattomaan tapaukseen.

Ideaalikaasulain mukaisesti tiheys

$$
\rho=\frac{p}{R T}
$$

jossa $R$ on ilman kaasuvakio ja $T$ absoluuttinen lämpötila. Viskositeetti $\mu$ otaksutaan tässä vakioksi ja sen arvo voidaan laskea esimerkiksi Sutherlandin kaavasta. Ominaisentalpialle $h$ otetaan tavanomaiseen tapaan riippuvuus

$$
h \equiv e+\frac{p}{\rho}=c_{p} T
$$

jossa lämpökapasiteetti $c_{p}$ otaksutaan vakioksi. Todellisuudessa viskositeetti ja lämpökapasiteetti riippuvat tietenkin lämpötilasta, mutta käsittelyn yksin-kertaistamiseksi tämä jätetään huomiotta.

Kuten edellä tarkastellaan pysyvää virtausta. Virtausta kuvaaviksi perussuureiksi otetaan paine $p(x)$, tilavuusvirta $Q(x)=\left\langle v_{e}(x)\right\rangle A$ ja poikkileikkauksen niin sanottu keskilämpötila $T(x)$ lähteen [2, s. 383] mukaisesti.

Ajatellaan, että kyseinen kanavisto-osuus on osa yleisempää kanavistoa. Paine $p_{1}$, tilavuusvirta $Q_{1}$ ja lämpötila $T_{1}$ poikkileikkauksessa 1 ajatellaan tunnetuiksi. Tehtävänä on määrittää vastaavat arvot $p_{2}, Q_{2}$ ja $T_{2}$ poikkileikkauksessa 2. Kuitenkin aluksi esitetään niin sanottu isoterminen (kokoonpuristumaton) tapaus, jossa $p_{1}$ ja $Q_{1}$ otaksutaan tunnetuiksi ja on määritettävä vain $p_{2}$ ja $Q_{2}$.

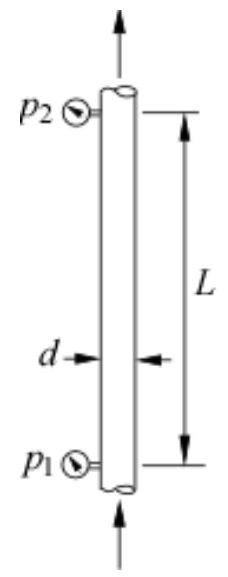

Kuva 2. Kanavaosuus.

\section{Isoterminen tapaus}

Kahden tuntemattoman suureen $p_{2}$ ja $Q_{2}$ määrittämiseksi tarvitaan kaksi yhtälöä. Isotermisessä formulaatiossa erityisesti mahdollinen lämpötilan muutoksen vaikutus jäte- 
tään huomiotta ja tiheyden $\rho_{1}=\rho$ otaksutaan olevan vakio. Kaksi tarvittavaa yhtälöä ovat massan säilymisen periaate ja mekaanisen energian taseen periaate.

Ensimmäinen yhtälö. Massatase antaa yhtälön

$$
\rho Q_{1}=\rho Q_{2}
$$

eli tilavuusvirta poikkileikkauksissa 1 ja 2 on sama:

$$
Q_{2}=Q_{1} \equiv Q .
$$

Toinen yhtälö. Edellisen perusteella saadaan keskinopeuksiksi

$$
\left\langle v_{e}\right\rangle_{1}=\frac{Q_{1}}{A_{1}}=\frac{Q}{A}, \quad\left\langle v_{e}\right\rangle_{2}=\frac{Q_{2}}{A_{2}}=\frac{Q}{A}
$$

eli myös $\left\langle v_{e}\right\rangle_{2}=\left\langle v_{e}\right\rangle_{1}$. Kun otaksutaan lisäksi, että liike-energian korjaustekijät ovat yhtäsuuret $\left(\alpha_{1}=\alpha_{2}\right)$, liike-energiatermit häviävät yhtälössä (4) ja päädytään yhtälöön

$$
\Delta p+\rho g\left(z_{1}-z_{2}\right)=\frac{D}{Q}
$$

jossa $\Delta p=p_{1}-p_{2}$. Täten $\Delta p$ ja toinen tuntematon $p_{2}$ voidaan määrittää suoraan yhtälöstä (13). Tarvitaan kuitenkin arvio häviötermistä $D$. Käytetään tunnettua muotoa

$$
D=f \frac{L}{d} \frac{1}{2} \rho\left(\frac{Q}{A}\right)^{2} Q
$$

jossa niin sanotun kitkatekijän (engl. friction factor) $f$ lauseke on ([3])

$$
f=\frac{0.25}{\left[\log \left(\frac{\varepsilon}{3.7 d}+\frac{5.74}{\mathrm{Re}^{0.9}}\right)\right]^{2}}
$$

Tässä $\varepsilon$ on kanaviston pinnankarheus (engl. roughness height) ja Re Reynoldsin luku:

$$
\operatorname{Re}=\frac{\rho d}{\mu}\left(\frac{Q}{A}\right)
$$

Yksityiskohtainen jatkokäsittely seuraa myöhemmin numeroarvojen yhteydessä.

\section{Lämpötilariippuva tapaus}

Nyt on siis lisäksi tarpeen myös varsinaisen energian taseen periaatteen käyttö.

Ensimmäinen yhtälö. Massatase antaa ensin yhteyden 


$$
\rho_{1} Q_{1}=\rho_{2} Q_{2}=w
$$

Konstitutiivista yhteyttä (8) soveltamalla saadaan sitten

$$
Q_{2}=\frac{\rho_{1}}{\rho_{2}} Q_{1}=\frac{p_{1} T_{2}}{p_{2} T_{1}} Q_{1}
$$

Toinen yhtälö. Mekaanisen energian taseen periaatteessa (4) täytyy ottaa huomioon kokoonpuristumistermin antama osuus. Käyttämällä liitteen kaavaa (L.2) eräiden termien nähdään kumoavan toisensa ja saadaan seuraavaksi

$$
Q_{1}\left[\alpha_{1} \frac{1}{2} \rho_{1}\langle v\rangle_{1}^{2}+\rho_{1} g z_{1}\right]-Q_{2}\left[\alpha_{2} \frac{1}{2} \rho_{2}\langle v\rangle_{2}^{2}+\rho_{2} g z_{2}\right]=D+\int_{0}^{L} Q \frac{\mathrm{d} p}{\mathrm{~d} x} \mathrm{~d} x-P_{\mathrm{s}} .
$$

Kun tämä jaetaan vielä puolittain massavirralla $w=\rho_{1} Q_{1}=\rho_{2} Q_{2}$ ja otetaan huomioon liitteen kaava (L.5) saadaan muoto

$$
\frac{Q_{\mathrm{m}}}{w} p_{1}+\alpha_{1} \frac{1}{2}\langle v\rangle_{1}^{2}+g z_{1}-\frac{Q_{\mathrm{m}}}{w} p_{2}-\alpha_{2} \frac{1}{2}\langle v\rangle_{2}^{2}-g z_{2}=\frac{D}{w}-\frac{P_{\mathrm{s}}}{w}
$$

Lopuksi tehdään vielä otaksuma $\alpha_{1}=\alpha_{2} \approx 1$ (tässä lisäksi $P_{\mathrm{S}}=0$ ). Saadaan yhtälö

$$
\frac{Q_{\mathrm{m}}}{w} \Delta p+\frac{1}{2}\left(\frac{Q_{1}}{A}\right)^{2}-\frac{1}{2}\left(\frac{Q_{2}}{A}\right)^{2}+g\left(z_{1}-z_{2}\right)=\frac{D}{w},
$$

jossa edelleen $\Delta p=p_{1}-p_{2}$. Häviötermi $D$ lasketaan kaavasta (14) käyttäen keskimääräisiä arvoja $\rho_{\mathrm{m}}=\left(\rho_{1}+\rho_{2}\right) / 2$ ja $Q_{\mathrm{m}}=\left(Q_{1}+Q_{2}\right) / 2$.

Kolmas yhtälö. Ottamalla huomioon ominaisentalpian lauseke (9) varsinainen energiayhtälö (3) saa ensin muodon

$$
Q_{1}\left[\alpha_{1} \frac{1}{2} \rho_{1}\langle v\rangle_{1}^{2}+\rho_{1} g z_{1}+\rho_{1} c_{p} T_{1}\right]-Q_{2}\left[\alpha_{2} \frac{1}{2} \rho_{2}\langle v\rangle_{2}^{2}+\rho_{2} g z_{2}+\rho_{2} c_{p} T_{2}\right]=-P_{\mathrm{Q}}-P_{\mathrm{s}}
$$

Kun tämä jaetaan vielä puolittain massavirralla $w$ ja tehdään jälleen otaksuma $\alpha_{1}=\alpha_{2} \approx 1$ (tässä edelleen $P_{\mathrm{s}}=0$ ), saadaan muoto

$$
c_{p} \Delta T+\frac{1}{2}\left(\frac{Q_{1}}{A}\right)^{2}-\frac{1}{2}\left(\frac{Q_{2}}{A}\right)^{2}+g\left(z_{1}-z_{2}\right)=-\frac{P_{\mathrm{Q}}}{w},
$$

jossa $\Delta T=T_{1}-T_{2}$. Systeemin saama lämpövirta $P_{\mathrm{Q}}$ tulee esittää jollain tavalla. Tässä otaksutaan, että kanaviston seinämällä on annettu vakiolämpötila $T_{s}$ ja että lämmönsiirtokertoimella $h$ (tässä eri suure kuin ominaisentalpia) on annettu vakioarvo. Lämpövuo (määriteltynä positiivisena ulos kontrollialueesta) on siis $q_{n}=h\left(T-T_{s}\right)$ ja ottaen huomioon poikkileikkauksen piirin arvo $P=\pi d$, systeemin saama lämpövirta on (poikki- 
leikkausten läpi tapahtuva lämpövuo jätetään tavanomaiseen tapaan huomiotta) [2, s. 397]

$$
P_{\mathrm{Q}}=h P L \Delta T_{1 \mathrm{~m}}
$$

jossa niin sanottu logaritminen keskilämpötilaero (engl. log mean temperature difference) on merkintöjämme käyttäen

$$
\Delta T_{\operatorname{lm}}=\frac{\left(T_{\mathrm{s}}-T_{2}\right)-\left(T_{\mathrm{s}}-T_{1}\right)}{\ln \left[\left(T_{\mathrm{s}}-T_{2}\right) /\left(T_{\mathrm{s}}-T_{1}\right)\right]} .
$$

Yhtälöt (18), (21) ja (23) ratkaistaan suureiden $Q_{2}, \Delta p$ (tai $p_{2}$ ) ja $\Delta T$ (tai $T_{2}$ ) suhteen. Ratkaisu vaatii iteraatiota. Käytetään laskentajärjestystä (23), (18), (21).

\section{Numeerinen sovellus}

Otetaan arvot

$$
\begin{aligned}
& L=4 \mathrm{~m}, \quad d=0.2 \mathrm{~m}, \quad z_{2}-z_{1}=4 \mathrm{~m}, \quad g=9.81 \mathrm{~m} / \mathrm{s}^{2}, \\
& \rho_{1}=1.20 \mathrm{~kg} / \mathrm{m}^{3}, \quad p_{1}=101300 \mathrm{~Pa}, \quad T_{1}=(273.15+20) \mathrm{K}, \\
& c_{p}=1005 \mathrm{~J} /(\mathrm{kg} \cdot \mathrm{K}), \quad \mu=0.0000185 \mathrm{~kg} /(\mathrm{m} \cdot \mathrm{s}), \\
& Q_{1}=0.1 \mathrm{~m}^{3} / \mathrm{s}, \quad \varepsilon=0.00009 \mathrm{~m}, \quad T_{\mathrm{s}}=(273.15+50) \mathrm{K} .
\end{aligned}
$$

Isotermisessä tapauksessa paine-eroksi saadaan

$$
\Delta p=50 \mathrm{~Pa} .
$$

Tilavuusvirta-arvo $Q_{2}=0.1 \mathrm{~m}^{3} / \mathrm{s}$ on tietenkin tässä itsestään selvä tulos. Paine-ero $\Delta p$ johtuu lähinnä painovoiman osuudesta ja dissipaatio-osuus $D / Q$ on vain noin $6 \%$ termistä $\rho g\left(z_{1}-z_{2}\right)$ yhtälössä (13).

Lämpötilariippuvassa tapauksessa lämmönsiirtokertoimen arvon määrittämiseksi on otettu Dittus-Boelterin yhtälön ([2, s. 406]) mukaisesti Nusseltin luvuksi (ilmalle Prandtlin luku $\operatorname{Pr} \approx 0.7$ )

$$
\mathrm{Nu}=0.023 \operatorname{Re}^{4 / 5} \operatorname{Pr}^{1 / 3}=0.023 \cdot 41292^{4 / 5} \cdot 0.7^{1 / 3}=100.64 .
$$

Tästä saadaan (ilmalle lämmönjohtavuus $k \approx 0.026 \mathrm{~W} /\left(\mathrm{m}^{2} \cdot \mathrm{K}\right)$ ) lämmönsiirto-kertoimeksi

$$
h=\frac{\mathrm{Nu} k}{d}=\frac{100.64 \cdot 0.026 \mathrm{~W} /(\mathrm{m} \cdot \mathrm{K})}{0.2 \mathrm{~m}} \approx 13 \mathrm{~W} /\left(\mathrm{m}^{2} \cdot \mathrm{K}\right) .
$$

Lämpötilariippuvassa tapauksessa iterointi antaa muun muassa logaritmiselle keskilämpötilaerolle arvon 


$$
\Delta T_{\mathrm{lm}}=26.28 \mathrm{~K}
$$

Samoin lopputuloksina saadaan arvot

$$
\Delta p=49.7 \mathrm{~Pa}, \quad Q_{2}=0.102 \mathrm{~m}^{3} / \mathrm{s}, \quad \Delta T=-7.13 \mathrm{~K} .
$$

Kuten nähdään, suhteellisen pienestä syntyneestä lämpötilaerosta $\Delta T=-7.13 \mathrm{~K}$ eli $T_{2}-T_{1}=7.13 \mathrm{~K}$ johtuen muutokset verrattuina isotermisen tapauksen tilavuusvirran ja paineen arvoihin ovat tässä erittäin pienet.

\section{Epätäsmällisyyksiä}

Energiakäsitteisiin liittyy helposti niiden monimuotoisuuden kuten liike-energia, potentiaalienergia, mekaaninen energia, sisäenergia, kokonaisenergia, lämpöenergia (joka on vältettävä termi) ja niin edespäin johdosta helposti väärinkäsitysten ja väärintulkintojen mahdollisuuksia ei vain arkikielen yhteydessä vaan myös tekniikan sovelluksissa. Seuraavassa esitetään eräs esimerkkitapaus.

Lähteessä [4]: "Handbook of Hydraulic Resistance, 790 s." annetaan suuri määrä tiettyjen virtausteknisten laitteiden osien geometrioihin liittyviä arvioita niin sanotuista häviöistä eli vastuksista (engl. loss, resistance). Seuraavassa on lainaus kirjan sivuilta 22 ja 23:

"1. According to the law of conservation of energy for the medium moving through a pipe (channel), the energy of the liquid (gas) flow passing through section $0-0$ per unit time (see Figure 1-10) is equal to the sum of energies of the liquid (gas) flow passing through section 1-1 per unit time plus the internal (thermal) and mechanical energies dissipated along the segment between these sections.

2. In the general case of an inelastic (liquid) and elastic (gas) flow with nonuniform transverse velocity and pressure distribution, the corresponding energy equation will have the form

$$
\begin{aligned}
& \int_{F_{0}}\left(p+\frac{\rho w^{2}}{2}+g \rho z+\rho U\right) w d F= \\
& \int_{F_{1}}\left(p+\frac{\rho w^{2}}{2}+g \rho z+\rho U\right) w d F+\Delta N_{\text {tot }}
\end{aligned}
$$

where $z$ is the geometric height of the centroid of the corresponding section, in $\mathrm{m} ; p$ is the static pressure (absolute) at the point of the the corresponding section, in $\mathrm{Pa}, U$ is the internal specific heat energy of the gas flow (which a frictionless flow would have had), in $\mathrm{J} / \mathrm{kg}$; and $\Delta N_{\text {tot }}$ is the total power lost over the segment between 
sections $0-0$ and 1-1, which characterizes the value of mechanical energy dissipated into heat, in $\mathrm{W}$.

*Assuming no heat transfer and shaft work over the given segment."

Lainaus loppuu tähän. Kuvaa 1-10 ei ole liitetty tässä mukaan. Merkintöjen suhteen todettakoon vielä, että $w$ esittää tässä aksiaalista virtausnopeutta (engl. stream velocity). Tähdellä merkitty virke on kirjassa alaviitteenä. Tärkeä peruskaava (1-21) esiintyy kirjassa myöhemmin useassa eri muodossa johtuen kulloinkin tehdyistä otaksumista.

Mielestämme kirjan yhtälön (1-21) täytyy olla virheellinen. Kirjan tekstin perusteella on ilmeistä, että kyseessä on tarkoitus olla varsinaisen energiaperiaatteen eli termodynamiikan ensimmäisen pääsäännön sovellus. Tarkastellaan tilannetta yksinkertaisuuden vuoksi erityisesti kokoonpuristumattomassa tapauksessa, jolloin merkintöjämme käyttäen kaavan (7) mukaisesti dissipaatio $D=w\left(e_{2}-e_{1}\right)-P_{\mathrm{Q}}$. Yhtälössä (1-21) on jo mukana sisäenergian muutos (termin $U$ kautta) ja alaviitteen mukaisesti lämpötehon otaksutaan häviävän. Täten kaavan (7) oikea puoli esiintyy jo yhtälössä (1-21) eikä sinne saa enää lisätä ylimääräistä dissipaatiotermiä $\Delta N_{\text {tot }}$.

Esittämämme kritiikki ei poista kirjan tärkeää käytännöllistä arvoa, koska useimmissa sovelluksissa on kuitenkin itse asiassa kyse mekaanisen energian taseen periaatteen käytöstä, koska sisäenergian ja lämmönsiirron osuutta ei ole mukana. Voidaan myös todeta, että lainauksessa esiintyvä teksti "which characterizes the value of mechanical energy dissipated into heat" on nykyterminologian mukaan harhaanjohtava, koska termi "heat" eli lämpö on kappaleen (systeemin) saama tai luovuttama energia. Lainauksen loppu kuuluisi paremmin: "dissipated into internal energy".

\section{Kiitokset}

Kiitämme käsikirjoituksen vertaisarvioijia korjausehdotuksista, joiden huomioonotto on mielestämme parantanut artikkelin sisältöä.

\section{Viitteet}

[1] Salonen, E-M. ja Holopainen, R. (2014). Makroskooppiset energiataseet virtauslaskennassa, Rakenteiden Mekaniikka, vol. 47, nro. 4, s. 127-147. http://rmseura.tkk.fi/rmlehti/2014/nro4/RakMek_47_4_2014_1.pdf

[2] Incroprera F. D. and DeWitt D. P (1981). Fundamentals of Heat Transfer, Wiley.

[3] Swamee, P. K. and Jain. A. K. (1976). Explicit Equations for Pipe-Flow Problems, Journal of Hydraulics Division, ASCE, Vol. 102, No. HY5, pp. 657-664.

[4] Idelchik, I. E. (2003) Handbook of Hydraulic Resistance, 3rd ed. Jaico.

[5] Bird, R.B., Stewart W.E. and Lightfoot. E.N. (2002). Transport Phenomena, 2nd ed. Wiley. 
Eero-Matti Salonen

Sibeliuksenkatu 3 B 25, 00250 Helsinki

eeromatti.salonen@gmail.com

Rauno Holopainen

Oulun ammattikorkeakoulu

Kotkantie 1, 90250 Oulu

rauno.holopainen@ oamk.fi 


\section{Liite}

Lähteessä [5] on osoitettu kaavana (7.8-12), että kokoonpuristuvuustermiä voidaan approksimoida muodossa (käyttäen merkintöjämme)

$$
-\int_{V} p d_{i i} \mathrm{~d} V \approx-w\left[\left.\frac{p}{\rho}\right|_{0} ^{L}-\int_{0}^{L} \frac{1}{\rho} \frac{\mathrm{d} p}{\mathrm{~d} x} \mathrm{~d} x\right] .
$$

Kaavan johdossa on eräänä otaksumana, että virtaukseen voidaan liittää jonkinlainen aksiaalinen "edustava virtaviiva" (engl. representative streamline). Sovellukseemme liittyen tämä otaksuma on voimassa. Ottamalla huomioon massavirran lauseke $w=\rho Q=\rho_{1} Q_{1}=\rho_{2} Q_{2}$ kaava (L.1) on vaihtoehtoisesti

$$
-\int_{V} p d_{i i} \mathrm{~d} V \approx-p_{2} Q_{2}+p_{1} Q_{1}+\int_{0}^{L} Q \frac{\mathrm{d} p}{\mathrm{~d} x} \mathrm{~d} x .
$$

Tässä otaksutaan edelleen (ei enää lähteen [5] otaksuma), että esiintyvän integraalin määrittämisessä suureita $p$ ja $Q$ voidaan approksimoida lineaarisesti aksiaaalisen pituuskoordinaatin $x$ suhteen:

$$
\begin{aligned}
& p(x) \approx\left(1-\frac{x}{L}\right) p_{1}+\frac{x}{L} p_{2}, \\
& Q(x) \approx\left(1-\frac{x}{L}\right) Q_{1}+\frac{x}{L} Q_{2} .
\end{aligned}
$$

Täten derivaatta $\mathrm{d} p / \mathrm{d} x=\left(p_{2}-p_{1}\right) / L$ on $x:$ n suhteen vakio ja siis

$$
\begin{gathered}
\int_{0}^{L} Q \frac{\mathrm{d} p}{\mathrm{~d} x} \mathrm{~d} x \approx \frac{p_{2}-p_{1}}{L} \int_{0}^{L}\left[\left(1-\frac{x}{L}\right) Q_{1}+\frac{x}{L} Q_{2}\right] \mathrm{d} x=\frac{p_{2}-p_{1}}{L} \frac{Q_{1}+Q_{2}}{2} L \\
=\left(p_{2}-p_{1}\right) \frac{Q_{1}+Q_{2}}{2} \equiv\left(p_{2}-p_{1}\right) Q_{\mathrm{m}},
\end{gathered}
$$

jossa $Q_{\mathrm{m}}$ on keskimääräinen tilavuusvirta. Soveltamalla lauseketta (L.5) kaavassa (L.2) saadaan lopuksi approksimaatio

$$
-\int_{V} p d_{i i} \mathrm{~d} V \approx p_{2}\left(Q_{\mathrm{m}}-Q_{2}\right)+p_{1}\left(Q_{1}-Q_{\mathrm{m}}\right) .
$$

Tämä on looginen ainakin siinä mielessä, että kokoonpuristumattomassa virtauksessa, jolloin $d_{i i}=0$, myös kaavan oikea puoli häviää, koska silloin $Q_{1}=Q_{2}=Q_{\mathrm{m}}$. 